\title{
Atypical Fibroxanthoma of the Conjunctiva in Xeroderma Pigmentosum
}

\author{
Nabeel Shalabi ${ }^{a}$ d Anat Galor ${ }^{a}$ b Sander R. Dubovy ${ }^{a, c}$ \\ Jordan Thompson $^{a} \quad$ J. Antonio Bermudez-Magner ${ }^{a}$ Carol L. Karpa \\ ${ }^{a}$ Bascom Palmer Eye Institute, University of Miami Miller School of Medicine, \\ ${ }^{b}$ Miami Veterans Affairs Medical Center, and ' Florida Lions Ocular Pathology Laboratory, \\ Miami, Fla., USA; dFaculty of Medicine, Hail University, Hail, Saudi Arabia
}

\section{Key Words}

Atypical fibroxanthoma - Xeroderma pigmentosum · Skin tumor - Malignant fibrous histiocytoma

\section{Abstract}

Background: Atypical fibroxanthoma (AFX) is a pleomorphic tumor that most commonly presents in the elderly and arises on sun-exposed skin. Methods: We report a case of a 24-year-old white male with xeroderma pigmentosum (XP), who developed an AFX of the conjunctiva, and review the literature. Results: The patient presented with a rapidly growing conjunctival mass which was surgically excised and found to be AFX. The patient has done well with no recurrence. A review of the literature was performed, and we found that only one other case has been published so far. Conclusion: Patients with XP may present with unusual tumors, including nonepithelial soft-tissue tumors. AFX is a rapidly growing tumor which may rarely present on the ocular surface.

\section{Introduction}

Atypical fibroxanthoma (AFX) is a benign skin tumor of mesenchymal origin that most commonly occurs on the head and neck of elderly individuals. The association with ultraviolet (UV) radiation explains the typical location in sun-exposed areas. As it can present as a solitary nodule of variable color, the definitive diagnosis is made on histopathology with the aid of 
Fig. 1. External photograph of the patient demonstrating multiple skin lesions and exenterated left eye.
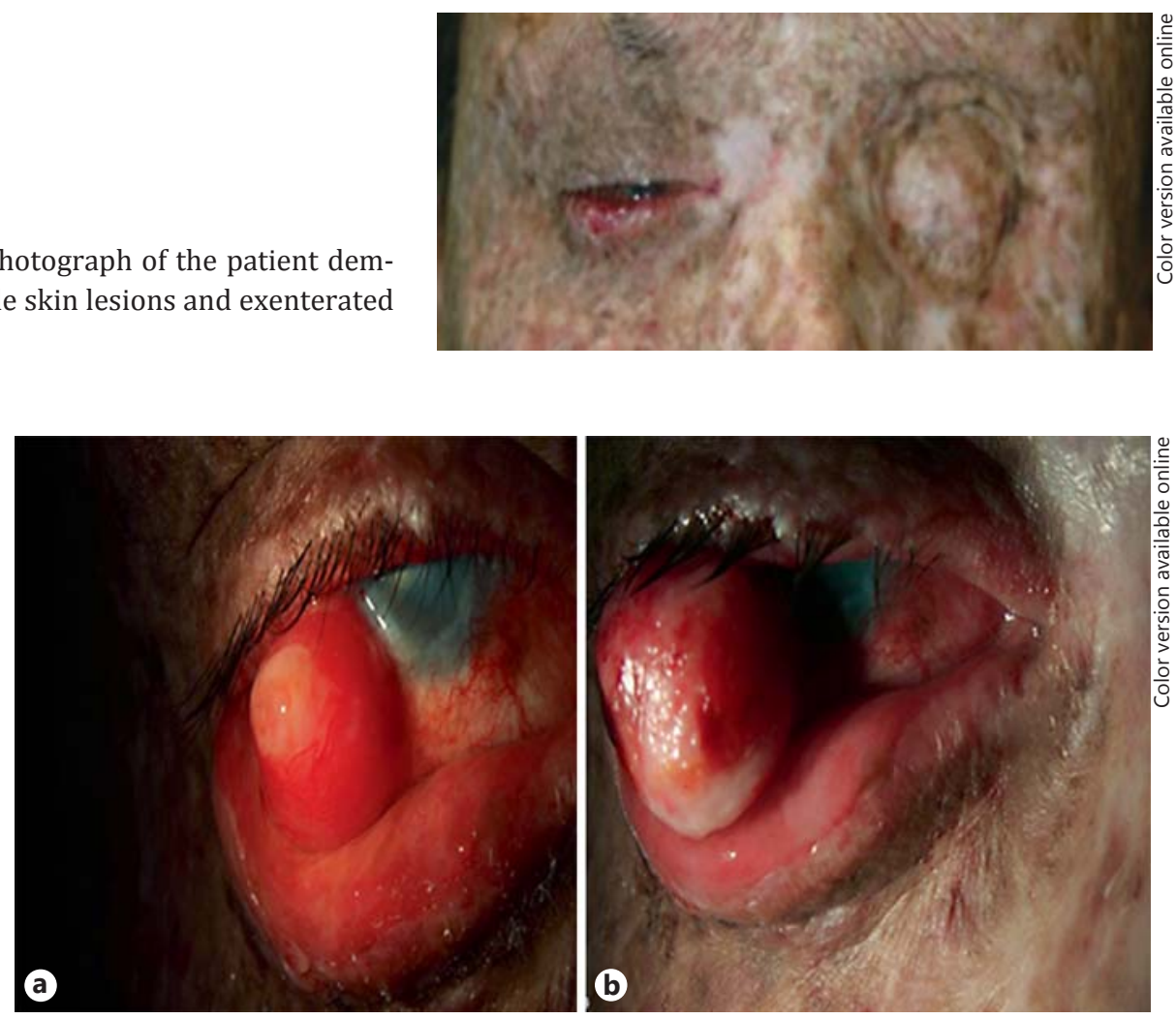

Fig. 2. a Right eye with AFX of the conjunctiva revealing a soft, pink lesion on the lateral limbus. b Nine days after the first presentation, the lesion had rapidly enlarged.

immunohistochemical studies. The tumor is very amenable to surgical resection and rarely recurs [1].

Xeroderma pigmentosum (XP) is an autosomal recessive disorder characterized by an inability to repair damage caused by UV light. This is due to the decreased activity of nucleotide excision repair (NER) enzymes and, therefore, these patients incur increased UV-induced mutations. When tumor suppressor genes such as p53 are affected, these cells may have unchecked growth, with the resultant development of skin cancer [2-4]. This underlying enzymatic defect explains why patients with XP develop multiple skin and mucosal cancers at an early age. XP patients under the age of 20 years have an approximately 2,000-fold increased risk of developing basal cell carcinomas (BCC), squamous cell carcinomas (SCC), and melanomas compared to their nonaffected counterparts [5].

XP patients can present with a myriad of ophthalmic findings, most involving the formation of periocular and conjunctival cancers, the presence and treatment of which can lead to photophobia, conjunctivitis, and corneal scaring [6-8]. Despite the increased risk of epithelial neoplasias in these individuals, soft-tissue tumors are rarely seen in patients with XP. In fact, AFX has only rarely been described to affect XP patients. There are 4 cases of AFX with periorbital skin involvement reported so far (nose: $\mathrm{n}=1$, eyelid skin: $\mathrm{n}=2$, and cheek: $\mathrm{n}=1$ ) [9-12]. To our knowledge, there is only one previous report of AFX affecting the conjunctiva of a 5-year-old boy [13]. We report the second such case of a 24-year-old male with XP who developed a conjunctival AFX to highlight that XP patients may develop nonepithelial-based tumors. 
Ocular Oncology

and Pathology
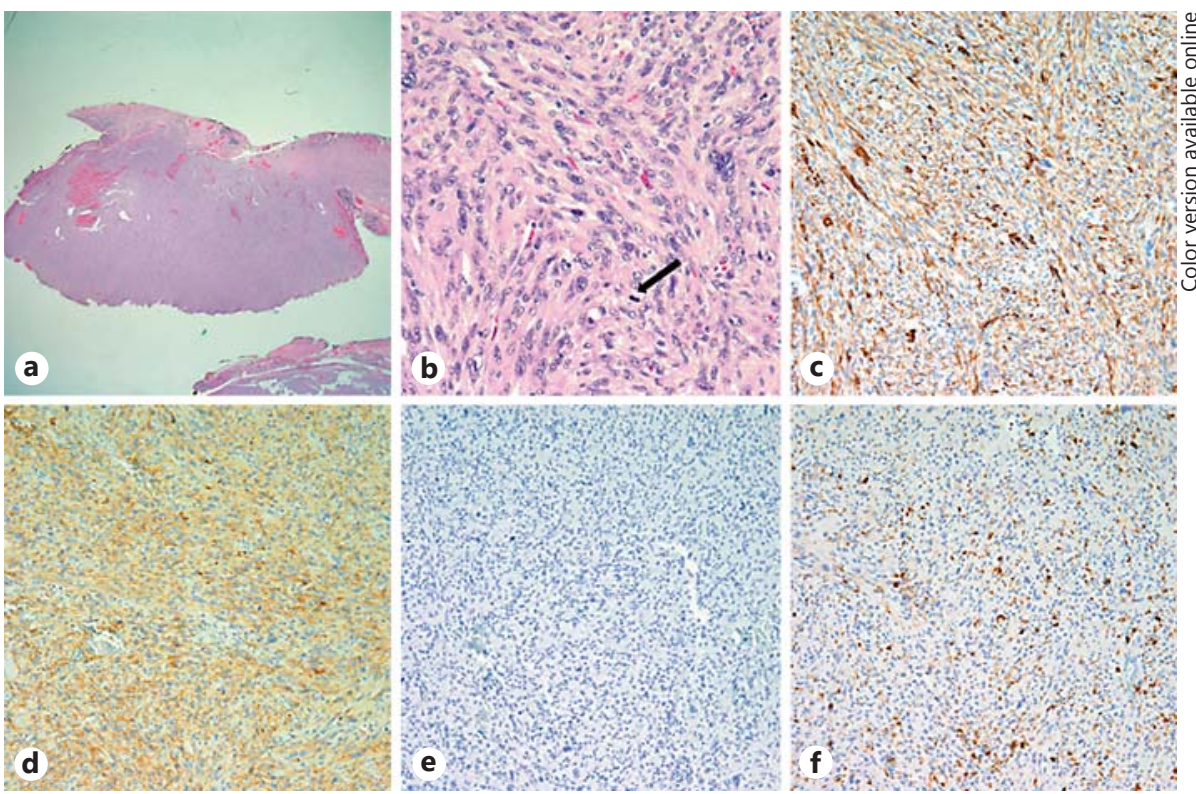

Fig. 3. a Low-magnification image disclosing conjunctiva that contains a well-circumscribed tumor composed of atypical cells within the substantia propria. $\mathbf{b}$ High-magnification image of the conjunctival tumor disclosing foci of cells with variably multinucleated prominent nucleoli and many atypical mitotic figures (arrow). c-f The tumor cells stain positive for SMA (c) and CD10 (d) and negative for melan A (e) and S-100 (f) (all from Dako, Carpinteria, Calif., USA). a, b Hematoxylin and eosin: $\times 40$ (a) and $\times 400$ (b). c-f $\times 200$.

\section{Case Presentation}

A 24-year-old white male with a history of XP had a past ocular and medical history of multiple skin cancers. He had multiple facial BCC, SCC, and a fibrous histiocytoma on the forehead. All facial skin cancers were treated with combined surgical excision, chemotherapy, and, in some cases, radiotherapy. In terms of ocular disease, the patient's left orbit was exenterated 11 years prior due to extensive orbital SCC. Since then, he had developed several right eyelid, conjunctival, and corneal pathologies including SCC of the eyelids, ocular surface squamous neoplasia (OSSN), pterygium, cicatricial ectropion from the prior surgeries, and corneal scaring secondary to exposure.

The patient then presented with a rapidly enlarging lesion on the right conjunctiva. On external examination, multiple hypo- and hyperpigmented skin lesions were noted on the skin, along with nose and mouth deformities from multiple prior surgical excisions. The left orbit had been exenterated (fig. 1). Ophthalmic examination of the right eye revealed a visual acuity of $20 / 300$. On slit lamp examination, a $22 \times 16 \times 5 \mathrm{~mm}$ pedunculated, soft, pink lesion was noted on the lateral limbus (fig. 2a).The patient was scheduled for a surgical excision and returned 9 days later for the procedure. Clinical examination revealed that the lesion had dramatically increased in size compared to the previous visit (fig. $2 \mathrm{~b}$ ). The patient underwent surgical excision with cryotherapy, amniotic membrane transplant, and map biopsies of the right conjunctiva.

Microscopic examination disclosed a tumor composed of atypical cells within the substantia propria that contained foci of variably multinucleated prominent nucleoli with atypical mitotic figures (fig. 3). The tumor extended to the deep margin of the central aspect of the lesion. Immunohistochemical studies revealed that the cells stained positive for smooth muscle actin (SMA), CD10, and CD99 and negative for mucicarmine, cytokeratin, melan A, and S-100. These histologic and immunohistochemical findings were consistent with a diagnosis of AFX. One of the three map biopsies demonstrated a focus of OSSN. However, the lesion could not be appreciated clinically. The patient has had no recurrence of the AFX for 4 years. 
Ocular Oncology

and Pathology \begin{tabular}{l|l}
\hline Ocul Oncol Pathol 2015;1:254-258 \\
\hline DOI: $10.1159 / 000377682$ & $\begin{array}{l}\text { C } 2015 \text { S. Karger AG, Basel } \\
\text { www.karger.com/oop }\end{array}$ \\
\hline \multicolumn{2}{l}{ Shalabi et al.: Atypical Fibroxanthoma of the Conjunctiva in Xeroderma Pigmentosum }
\end{tabular}

\section{Discussion}

Patients with XP have sensitivity to UV radiation that leads to the development of cancerous lesions in sun-exposed skin. Previous studies have revealed that the most common skin tumor in patients with XP is SCC, followed by BCC [8]. In the conjunctiva, the most common primary malignant tumor is OSSN [14]. Similar to non-XP patients, the OSSN is predominantly found in the limbal region. Soft-tissue tumors, on the other hand, are not commonly seen in XP patients. One previous case report described an AFX of the conjunctiva in a 5-year-old boy with XP [13]. This patient had a history of invasive SCC of the conjunctiva in both eyes. The boy presented with a small elevated conjunctival lesion near the medial canthus of the right eye. Three months later, the patient had sudden pain and bleeding from the right eye. Ophthalmic examination revealed a laceration of the conjunctiva and pedunculated hematoma within the new lesion. The lesion was excised under general anesthesia. Immunohistochemical studies confirmed the diagnosis of AFX. Our case is the second such report and highlights the need to consider that XP patients may present with nonepithelial-based tumors.

AFX is an uncommon tumor characterized by a benign clinical course and extremely rare metastasis. Clinically, AFX presents as a small dome-shaped or polypoid nodule which undergoes rapid growth. The lesion may be flesh-colored, white, or erythematous and may have areas of ulceration and/or bleeding. Microscopically, AFX is often well circumscribed and does not extend into the subcutaneous tissue. AFX is comprised of multinucleated cells in hypercellular spindled stroma with frequent atypical mitotic figures. AFX often shows fibroblastic, myofibroblastic, and histiocyte-like cells with pleomorphism. The tumor typically stains positive for vimentin, SMA, alpha-1 antitrypsin, CD68, CD99, and CD10 and negative for cytokeratin, EMA, S-100, HMB45, and desmin.

Malignant fibrous histiocytoma (MFH) is another soft-tissue tumor that can be confused with AFX histologically. Clinically, MFH behaves differently than AFX with a more aggressive clinical course and a higher frequency of metastasis. Interestingly, MFH is not associated with actinic damage and can occur anywhere on the body. While AFX is identical to MFH histologically, their differentiating aspect is that AFX is centered in the dermis, while MFH shows an appreciable extension into the subcutaneous fat, perineural infiltration, and lymphovascular invasion. In addition to the differences described, further evidence that the tumor in this case was indeed AFX is that it did not recur over 4 years of follow-up. In contrast to the benign course of AFX, MFH is more likely to recur, with a 5-year mortality rate of 50\% [15]. MFH of the skin and conjunctiva has been described in a 3-year-old XP patient [16].

\section{Conclusion}

Patients with XP may present with unusual tumors, including nonepithelial soft-tissue tumors. AFX is a rapidly growing tumor which may rarely present on the ocular surface.

\section{Acknowledgment}

This work was supported by NIH Center Core Grant P30EY014801, Research to Prevent Blindness Unrestricted Grant, Department of Defense (DOD- Grant\#W81XWH-09-1-0675), and The Ronald and Alicia Lepke Grant, The Lee and Claire Hager Grant, The Jimmy and Gaye Bryan Grant, and The Richard Azar Family Grant (all institutional grants).

\section{Disclosure Statement}

The authors declare that they have no conflicts of interest. 
Shalabi et al.: Atypical Fibroxanthoma of the Conjunctiva in Xeroderma Pigmentosum

\section{References}

1 Mirza B, Weedon D: Atypical fibroxanthoma: a clinicopathological study of 89 cases. Australas J Dermatol 2005;46:235-238.

2 Dei Tos AP, Maestro R, Doglioni C, Gasparotto D, Boiocchi M, Laurino L, Fletcher CD: Ultraviolet-induced p53 mutations in atypical fibroxanthoma. Am J Pathol 1994;145:11-17.

3 Oshiro Y, Fukuda T, Tsuneyoshi M: Atypical fibroxanthoma versus benign and malignant fibrous histiocytoma. A comparative study of their proliferative activity using MIB-1, DNA flow cytometry, and p53 immunostaining. Cancer 1995;75:1128-1134.

4 Sakamoto A, Oda Y, Itakura E, Oshiro Y, Nikaido O, Iwamoto Y, Tsuneyoshi M: Immunoexpression of ultraviolet photoproducts and p53 mutation analysis in atypical fibroxanthoma and superficial malignant fibrous histiocytoma. Mod Pathol 2001;14:581-588.

5 Kraemer KH, Lee MM, Scotto J: DNA repair protects against cutaneous and internal neoplasia: evidence from xeroderma pigmentosum. Carcinogenesis 1984;5:511-514.

6 Goyal JL, Rao VA, Srinivasan R, Agrawal K: Oculocutaneous manifestations in xeroderma pigmentosa. Br J Ophthalmol 1994;78:295-297.

7 Hertle RW, Durso F, Metzler JP, Varsa EW: Epibulbar squamous cell carcinomas in brothers with Xeroderma pigmentosa. J Pediatr Ophthalmol Strabismus 1991;28:350-353.

8 Kraemer KH, Lee MM, Scotto J: Xeroderma pigmentosum. Cutaneous, ocular, and neurologic abnormalities in 830 published cases. Arch Dermatol 1987;123:241-250.

9 Patterson JW, Jordan WP Jr: Atypical fibroxanthoma in a patient with xeroderma pigmentosum. Arch Dermatol 1987;123:1066-1070.

10 Bandyopadhyay R, Nag D, Bandyopadhyay S, Sinha SK: Atypical fibroxanthoma: an unusual skin neoplasm in xeroderma pigmentosum. Indian J Dermatol 2012;57:384-386.

11 Dilek FH, Akpolat N, Metin A, Ugras S: Atypical fibroxanthoma of the skin and the lower lip in xeroderma pigmentosum. Br J Dermatol 2000;143:618-620.

12 Youssef N, Vabres P, Buisson T, Brousse N, Fraitag S: Two unusual tumors in a patient with xeroderma pigmentosum: atypical fibroxanthoma and basosquamous carcinoma. J Cutan Pathol 1999;26:430-435.

13 Shao L, Newell B, Quintanilla N: Atypical fibroxanthoma and squamous cell carcinoma of the conjunctiva in xeroderma pigmentosum. Pediatr Dev Pathol 2007;10:149-152.

14 Lee GA, Hirst LW: Ocular surface squamous neoplasia. Surv Ophthalmol 1995;39:429-450.

15 Ziemer M: Atypical fibroxanthoma (in English, German). J Dtsch Dermatol Ges 2012;10:537-550.

16 Pe'er J, Levinger S, Chirambo M, Ron N, Okon E: Malignant fibrous histiocytoma of the skin and the conjunctiva in xeroderma pigmentosum. Arch Pathol Lab Med 1991;115:910-914. 